\title{
Development of international standards to document sexual and reproductive functions after spinal cord injury: Preliminary report
}

\author{
Marcalee Sipski Alexander, MD; ${ }^{*}$ Donald Bodner, MD; ${ }^{2}$ Nancy L. Brackett, PhD, HCLD; ${ }^{3}$ Stacy Elliott, MD; $^{4}$ \\ Amie B. Jackson, MD; ${ }^{1}$ Jens Sønksen, MD, PhD, DMSci $^{5}$ \\ ${ }^{1}$ Physical Medicine and Rehabilitation, Spain Rehabilitation Center, University of Alabama at Birmingham, Birmingham, \\ $A L ;{ }^{2}$ Department of Urology, Case Western Reserve University School of Medicine, University Hospitals of Cleveland, \\ Cleveland, $\mathrm{OH} ;{ }^{3}$ The Miami Project to Cure Paralysis, University of Miami Miller School of Medicine, Miami, FL; \\ ${ }^{4}$ Departments of Psychiatry and Urology, University of British Columbia (BC), BC Center for Sexual Medicine, Vancouver, \\ BC, Canada; ${ }^{5}$ Department of Urology, Herlev Hospital, University of Copenhagen, Copenhagen, Denmark
}

\begin{abstract}
Clinicians need standard terminology to communicate effectively about remaining autonomic function in persons after spinal cord injury. This article illustrates the development of standard nomenclature that describes the impact of injury on sexual functioning. A standard anatomic diagnosis and a secondary means of describing the presence of male and female sexual dysfunction, genital arousal, and orgasmic function are discussed.
\end{abstract}

Key words: arousal, assessment, female, fertility, male, menstruation, orgasm, sexuality, sexual response, spinal cord, standards.

\section{INTRODUCTION}

Communication about the effects of spinal cord injury (SCI) on motor and sensory functions is generally performed with the International Standards for Neurological Classification of Spinal Cord Injury of the American Spinal Injury Association (ASIA) [1]. In addition to clinicians using these standards to communicate the impact of SCI on neurological function, they have been using them as an outcome measure in a number of clinical trials to document the degree of remaining motor and sensory functions in persons with SCIs. However, these standards cannot be used to document the degree of preservation of autonomic function postinjury. In May 2004, ASIA appointed a working group to develop standards for professionals to communicate the characteristics of various aspects of autonomic function remaining in persons with SCIs. This group included international participants involved in clinical trials in SCI and basic science researchers. (See the Figure for members.) With the group's agreement, the autonomic standards being developed quickly evolved into International Autonomic Standards, rather than those of just ASIA. The working group transitioned into a steering committee, and subgroups were appointed to discuss bladder, bowel, and sexual and general autonomic functions. Individual subgroups functioned via Internet communication, and from 2004 to early 2005, each subgroup drafted a set of standards for its section. This article describes aspects of the preliminary draft of standards for documenting remaining sexual function of persons after SCI. This draft was presented at the ASIA meeting in May 2005.

Abbreviations: ART = assisted reproductive technology, ASIA = American Spinal Injury Association, IVF $=$ in vitro fertilization, $\mathrm{L}=$ lumbar, $\mathrm{S}=$ sacral, $\mathrm{SCI}=$ spinal cord injury, $\mathrm{T}=$ thoracic, $\mathrm{TMS}=$ total motile sperm.

* Address all correspondence to Marcalee Sipski Alexander, MD; Professor of Physical Medicine and Rehabilitation, Spain Rehabilitation Center, University of Alabama at Birmingham, SRC 510, 619 6th Ave S, Birmingham, AL 35249-7330; 205934-2022; fax: 205-996-5874. Email:msipski@uab.edu

DOI: $10.1682 / J R R D .2005 .10 .0166$ 


\section{Ad Hoc Committee}

Cochairs: Ralph J. Marino, MD, MCSE, and Marcalee Sipski Alexander, MD

Committee Members: Fin Biering-Sørensen, MD; Susan Charlifue, PhD; John F. Ditunno, Jr, MD; Daniel E. Graves, PhD; Lynne Weaver, DVM, PhD; Volker Dietz, MD, FRCP

\section{Urology Dimension}

Michael J. Kennelly, MD, Chairperson

Bruce Green, MD

Angelo E. Gousse, MD

Diana D. Cardenas, MD

Todd A. Linsenmeyer, MD

Graham H. Creasey, MD

Brigitte Schurch, MD

\section{Bowel Dimension}

Steven A. Stiens, MD, Chairperson

Irene M. Estores, MD

Inder Perkash, MD

Klaus Krogh, MD, PhD

\section{Sexual Function Dimension}

Marcalee Sipski Alexander, MD

Stacy Elliott, MD

Amie B. Jackson, MD

Donald Bodner, MD

Nancy L. Brackett, PhD

Jens Sønksen, MD, PhD, DMSci

General Autonomic Function Dimension

Andrei V. Krassioukov, MD, PhD, Chairperson

Ann-Katrin Karlsson, MD, PhD

Lisa-Ann Wuermser, MD

Jill M. Wecht, PhD

Christopher J. Mathias, MD, PhD

\section{Figure.}

Members of international working group appointed by American Spinal Injury Association to develop standards for professionals to communicate characteristics of autonomic function in persons after spinal cord injury.

\section{INTERNATIONAL SEXUAL AND REPRODUCTIVE FUNCTION STANDARDS}

While sex is a basic human need and leads to procreation and the maintenance of humanity, it is a unique system in that it is "optional." As a basic human need, sex can be for pleasure or reproduction. Furthermore, some physiological and interpretive differences are apparent between the sexual response in males and that in females. In light of these important issues, the group concurred that the International Standards to document sexual function after SCI should include four separate subsets to be used as appropriate for different categories of sexual function. These subsets include male sexual response, male reproductive function, female sexual response, and female reproductive function. Because each group member had expertise in a different area, various individuals or groups addressed the process by developing a set of recommended items to include in their particular areas of expertise, and then each group concurred on the entire product.

\section{SEXUAL FUNCTION}

Sexual function categories pertain to sexual response and sexual activity, not fertility. In this area, "sexual dysfunction" is unique from other physiological dysfunctions because alterations in response are not considered problematic unless they cause personal distress [2]. Thus, a separate category of sexual dysfunction and the ability to describe the presence of specific sexual dysfunctions is included under both male and female sexual and reproductive functions.

\section{Male Sexual Function}

See Table 1 for the recommended standard format to describe male sexual response, along with accompanying definitions. Recently, the use of physiological studies to document the effects of SCI on male sexual response has increased. Based on this research, the potential for psychogenic erection is likely related to preservation of sympathetic function to the genitals [3-4]. Until this finding is further documented, psychogenic erection is recommended to be described as present, possible though partially impaired, or absent based on patient report or physiological data, whether available or not (Table 1). Similarly, the potential for reflex erection is apparently based on the presence of reflex function in the sacral level 2 (S2) to S5 spinal segments [3-4]; however, for purposes of the standards, reflex function is recommended to be described as present, possible though partially impaired, or absent. Because ejaculation is most intimately associated with reproductive functioning, it is documented under reproductive function rather than sexual function. Last, the potential to experience orgasmic sensation is described based on history and can be listed as present, unknown, or absent. 


\section{Male Reproductive Function}

See Table 2 for the recommended standard format to describe male reproductive function, along with accompanying definitions. The possibility for men to father children after SCI has changed tremendously in the past 20 years, largely because of clinicians' ability to stimulate ejaculation through assisted methods [5]. Thus, in men with SCI who are pursuing fertility, documenting the capacity for seminal emission or ejaculation through natural or medically assisted methods is important. The ability to produce antegrade ejaculation through sexual stimulation without vibratory stimulation is first recorded [6-7]. This ability, with normal forward projection as before injury, can be present, partially present, or absent (Table 2). The latter two categories may indicate partial or complete retrograde ejaculation, incomplete propulsatile ejaculation, or anejacu- lation. The ability to undergo successful sperm retrieval is next documented, recorded as unknown, possible, or not possible. If possible, retrieval can be successful through assisted ejaculation (i.e., medication-enhanced, sexual aids other than vibrostimulation), penile vibratory stimulation, or electroejaculation [8-9]. Whether men experience autonomic dysreflexia with ejaculation in either private or sperm-retrieval clinic settings should be recorded and also the level of severity, because the occurrence of severe dysreflexia may alter recommended methods of sperm obtainment. If obtaining sperm is possible through surgical means, one should record how and where the sperm is able to be obtained. This could include testicular sperm aspiration, testicular sperm extraction, or other sites of sperm extraction including the epididymis or vas deferens.

Table 1.

Characteristics of sexual response in males after spinal cord injury (SCI).

\begin{tabular}{|c|c|c|}
\hline Function & Primary Response Options & Subclassification \\
\hline \multicolumn{3}{|l|}{ Erection } \\
\hline Psychogenic & Present, possible though impaired, absent & - \\
\hline Reflex & Present, possible though impaired, absent & - \\
\hline Sexual Dysfunction & Present, absent & Desire, erectile, ejaculatory, or orgasmic dysfunction \\
\hline \multicolumn{3}{|c|}{ Ejaculation = Forceful propulsion of semen externally from penis. } \\
\hline \multicolumn{3}{|c|}{$\begin{array}{l}\text { Orgasm = Perception of feeling peak physiological or mental excitement, sense of release of high arousal, or reaching climax, after which person with SCI feels satisfied } \\
\text { and no longer desires further sexual stimulation. May be accompanied by overall increase and then decrease in muscle tone. }\end{array}$} \\
\hline \multirow{2}{*}{\multicolumn{3}{|c|}{$\begin{array}{l}\text { Psychogenic erection = Erection that occurs solely based on arousal in brain, e.g., through hearing, seeing, feeling, or imagining erotic thoughts. } \\
\text { Reflex erection = Erection that occurs solely based on genital or sacral stimulation. }\end{array}$}} \\
\hline & & \\
\hline \multicolumn{3}{|c|}{$\begin{array}{l}\text { Sexual dysfunction = Complaint of specific sexual problem based on history and presence of personal distress. This may include desire, erectile dysfunction, ejacula- } \\
\text { tory, or orgasmic dysfunction. }\end{array}$} \\
\hline
\end{tabular}

Table 2.

Characteristics of reproductive function in males after spinal cord injury.

\begin{tabular}{lll}
\hline \multicolumn{1}{c}{ Function } & Primary Response Options & Subclassification \\
\hline $\begin{array}{l}\text { Antegrade Ejaculation } \\
\text { Rerm }\end{array}$ & Present, partial, absent & - \\
& Unknown, possible, not possible & $\begin{array}{l}\text { Assisted ejaculation, vibratory stimulation, electroejacu- } \\
\text { lation, surgery. Also, indicate whether autonomic dysre- } \\
\text { flexia accompanies procedure of choice. }\end{array}$ \\
$\begin{array}{lll}\text { Count } \\
\text { Assisted Reproductive Techniques }\end{array}$ & $\begin{array}{l}\text { Good, fair, poor } \\
\text { Unknown, possible, not possible }\end{array}$ & $\begin{array}{l}\text { Indicate methods used: home intravaginal insemina- } \\
\text { tion, intrauterine insemination, in vitro fertilization } \\
\text { (IVF), IVF/intracytoplasmic sperm injection. }\end{array}$ \\
\hline
\end{tabular}

\footnotetext{
Antegrade ejaculation = Ejaculation through penis through sexual stimulation without associated vibratory stimulation.

Sperm count (includes both antegrade and retrograde fractions):

Good $=20$ million total motile sperm (TMS) per ejaculate.

Fair $=4-20$ million TMS per ejaculate.

Poor $=4$ million TMS per ejaculate.

Sperm retrieval = Ability to retrieve sperm through assisted techniques based on number of TMS per ejaculate, including antegrade and/or retrograde fractions.
} 
The presence of sperm is also documented as present or absent, and the count is graded if present [10-11] as good, fair, or poor based on total motile sperm (TMS) per ejaculate, including antegrade and/or retrograde fractions. A good sample has 20 million TMS per ejaculate, a fair sample has 4 to 20 million TMS per ejaculate, and a poor sample has 4 million TMS per ejaculate.

The use of and success with assisted reproductive technologies (ARTs) are also listed as possible or not possible if the person has no testicular function. If possible, the type of ART used is documented, including home intravaginal insemination, intrauterine insemination, in vitro fertilization (IVF), and IVF/intracytoplasmic sperm injection [11].

\section{Female Sexual Function}

See Table 3 for the recommended standard format to describe female sexual response, along with accompanying definitions. Over the past 10 years, substantial research has been conducted to study whether remaining sensory function could be used to predict psychogenic genital arousal [12-13]. A number of studies have supported the hypothesis that the maintenance of psychogenic genital arousal could be predicted on the basis of the ability to perceive combined pinprick and sensory function in the thoracic level 11 (T11) to lumbar level 2 (L2) dermatomes [5,14-15]. In this area of the spinal cord, the cell bodies produce the sympathetic innervation of the genitals. Thus, when clinicians are performing physical examinations, they should give special attention to the T11 to L2 dermatomes when performing a neurological examination after SCI to document remaining female sexual potential.
Based on this examination and historical report, psychogenic arousal is documented as present, possible though partially impaired, or absent (Table 3).

Reflex genital arousal has also been studied, and research has supported the hypothesis that the potential for this function is based on presence of intact reflex function in S2 to S5 spinal cord segments [5-6,16]. On the basis of a physical examination and historical report, reflex arousal is described as present, possible though partially impaired, or absent (Table 3). The potential to experience the sensation of orgasm has been documented extensively in women with SCIs [5,17-20]. Furthermore, the ability to achieve orgasm has been found significantly diminished in women with complete lower motor neuron injuries affecting their S2 to S5 spinal segments as compared with all other levels and degrees of injuries [5]. Therefore, clinicians are advised to document the potential for orgasmic response and to give special attention to the physical examination of this area of the spinal cord. Those persons with intact bulbocavernosus and or anal wink reflexes should have the potential to experience the sensation of orgasm, whereas women without S2 to S5 sensation and absent bulbocavernosus and anal wink reflexes should not.

\section{Female Reproductive Function}

Table 4 details the recommended standard format with accompanying definitions for describing female reproductive function [21-23]. The status of reproductive functioning of women after SCI is affected by many non-SCI as well as SCI factors. A woman's ability to conceive may be affected immediately after injury if she experiences reproductive endocrine changes [12,24]. However, despite that

Table 3.

Characteristics of sexual response in females after spinal cord injury (SCI).

\begin{tabular}{|c|c|c|}
\hline Function & Primary Response Options & Subclassification \\
\hline \multicolumn{3}{|l|}{ Genital Arousal } \\
\hline Psychogenic & Present, possible though impaired, absent & - \\
\hline Reflex & Present, possible though impaired, absent & - \\
\hline Orgasm & Present, possible though impaired, absent & - \\
\hline Sexual Dysfunction & Present, absent & Desire, arousal, orgasmic, or pain dysfunction \\
\hline \multicolumn{3}{|c|}{ Genital arousal = Increased genital vasocongestion that usually manifests itself with presence of clitoral engorgement and vaginal lubrication, amongst other signs. } \\
\hline \multicolumn{3}{|c|}{$\begin{array}{l}\text { Orgasm = Perception of sensation of feeling good from sexual stimulation, reaching climax, after which person with SCI feels satisfied and no longer desires further } \\
\text { sexual stimulation. May be accompanied by an overall increase and then decrease in muscle tone. }\end{array}$} \\
\hline \multicolumn{3}{|c|}{$\begin{array}{l}\text { Psychogenic genital arousal = Increased genital vasocongestion that occurs solely based on arousal in brain, e.g., through hearing, seeing, feeling, or imagining } \\
\text { erotic thoughts. }\end{array}$} \\
\hline \multicolumn{3}{|c|}{ Reflex genital arousal = Increased genital vasocongestion that occurs solely based on genital or sacral stimulation. } \\
\hline \multicolumn{3}{|c|}{$\begin{array}{l}\text { Sexual dysfunction = Alteration in aspect of sexual functioning that results in personal distress. If present, one should also indicate type of disorder: desire, arousal, } \\
\text { orgasmic, or pain. }\end{array}$} \\
\hline
\end{tabular}


Table 4.

Characteristics of reproductive function in females after spinal cord injury (SCI).

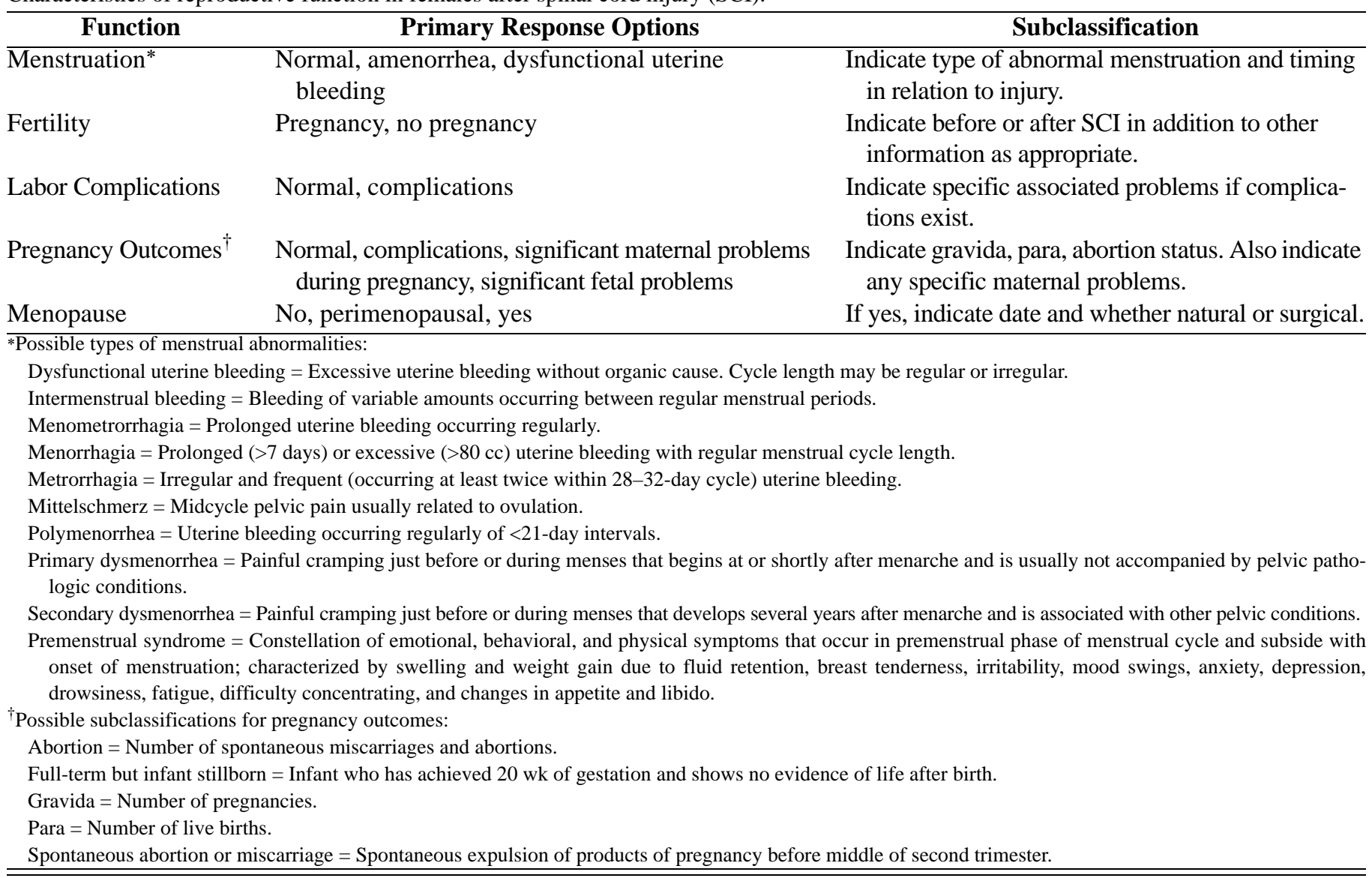

women with SCI are generally older when they have children (which may affect fertility) compared with their fertile nondisabled counterparts, apparently the ability to conceive is not under the autonomic control that is important in sexual function. Autonomic dysfunction, however, may affect labor and delivery. Since reproductive capacity depends on these issues, as well as the stage in life that the woman is experiencing, an expanded data set is recommended for individualized classification.

Menstruation has been studied in detail postinjury [2527] and is often disrupted. Thus, documenting the effects of SCI on menstruation is important. Also important to identify is whether the condition was present or absent before and after injury and whether the condition was present within or after 12 months postinjury. Menstruation can be classified as normal, amenorrhea, or dysfunctional uterine bleeding (Table 4). Menstruation can be further stratified into a normal hypothalamic-pituitary-ovarian axis that directs a regular cycle of average length or a normal cycle from the use of oral contraceptive hormones. A woman with amenorrhea may be further classified as premenarche, primary amenorrhea, nontraumatic secondary amenorrhea (which includes any type of secondary amenorrhea not related to spinal cord trauma), or traumatic secondary amenorrhea. Posttraumatic secondary amenorrhea is further classified on the basis of whether the return of menses is delayed $<3$ months post-SCI, $\geq 3$ months and $\leq 12$ months post-SCI, or $>12$ months post-SCI. Other causes for absence of menstruation should also be documented and include the date of hysterectomy without or with removal of ovaries, the date of menopause, and whether the woman is amenorrheic because of pregnancy.

Following SCI, women may develop hyperprolactinemia. Studies have reported as many as 60 percent of women may experience elevated prolactin levels and almost half these women will progress to galactorrhea [28-30]. Several studies have described a neurogenic amenorrheic-prolactinemia-galactorrhea syndrome [3132]. The autonomic repercussions of this syndrome have not been studied in women with SCI, but studies have 
shown that many of the neurotransmitters important in the sympathetic and parasympathetic nervous systems are involved in the hypothalamic-pituitary axis responsible for this phenomena [33-35]. Since autonomic symptoms of SCI may be exacerbated by hormonal fluctuations, SCIrelated symptoms should be documented and details provided, if available. Increased muscle spasticity, bladder spasms, bowel reflexes (with or without diarrhea), autonomic dysreflexia, or other autonomic symptoms can occur at specific times during the menstrual cycle. When researchers focus on the reproductive system for clinical trials, the elucidation of these patterns is important.

When an obstetric history is appropriate to include, fertility should be documented post-SCI. For women who have never been pregnant, reasons should be determined. Possibilities include never having had sex (i.e., virgin); never attempting pregnancy (by any means); attempted pregnancy (for at least 12 months), yet unable to conceive (for any reason of the woman); and finally, unable to conceive due to hysterectomy, sterilization, or infertility of male partner. For those women who have had pregnancies, the date of birth of each offspring should be documented. Furthermore, whether pregnancy was attained before or after 12 months postinjury and whether infertility medications were needed should be determined.

Pregnancy outcomes should be documented with details provided as appropriate. Outcomes can be normal, i.e., full-term pregnancy with live birth, or with complications such as spontaneous abortion or miscarriage, voluntary abortion, preterm birth, or full-term birth but infant stillborn [36]. Significant maternal problems during pregnancy can include preeclampsia, eclampsia, prolonged labor and delivery, gestational diabetes, frequent urinary tract infections, autonomic dysreflexia, severe spasticity, and a change in bladder function.

Labor symptoms for women with SCI should be documented as appropriate. Possible responses include none, normal uterine-contraction pain, ruptured membranes, abnormal pain not associated with uterine contraction, vaginal hemorrhaging, pain above the injury level, autonomic dysreflexia, and significantly increased spasticity.

The nerves important for lactation correspond to dermatome levels of T2 to T4. Thus, as appropriate, document whether lactation was attempted and was normal, not attempted, or attempted but insufficient breast milk was produced.

Menopause in nondisabled women is associated with autonomic instability [37] but may also be affected by SCI. At a minimum, including the date of menopause is appropriate. Further details may include documentation of normal menopause greater than 6 months before SCI, hysterectomy (with or without oophorectomy) before or after SCI, perimenopausal within 6 months before SCI but no periods after SCI, or regular menstruation within 6 months before SCI but no periods after SCI. Following an SCI, women may also experience menopause with or without postmenopausal dysautonomic symptoms.

\section{CONCLUSIONS}

We have presented a preliminary draft of a potential means to document the effects of SCI on sexual function as of 2005. Further work continued on these standards with the bladder, bowel, and general autonomic standards in June 2006 at the combined ASIA and International Spinal Cord Society meeting, and they are now available on the ASIA (http://www.asia-spinalinjury.org/) and International Spinal Cord Society Web sites (http://www.iscos.org.uk/). Because the standards are currently being developed, any comments or suggestions are appreciated and can be forwarded to the primary author of this article. Once developed, the standards will be validated and a training program developed to ensure their proper use.

\section{ACKNOWLEDGMENTS}

This material was unfunded at the time of manuscript preparation.

The authors have declared that no competing interests exist.

\section{REFERENCES}

1. American Spinal Injury Association. International Standards for Neurological Classification of Spinal Cord Injury, revised 2000. Chicago (IL): American Spinal Injury Association; 2002 (reprinted).

2. Basson R, Berman J, Burnett A, Derogatis L, Ferguson D, Fourcroy J, Goldstein I, Graziottin A, Heiman J, Laan E, Leiblum S, Padma-Nathan H, Rosen RC, Segraves K, Segraves RT, Shabsigh R, Sipski ML, Wagner G, Whipple B. Report of the international consensus development conference on Female Sexual Dysfunction: definitions and classifications. J Urol. 2000;163(3):888-93. [PMID: 10688007] 
3. Schmid DM, Curt A, Hauri D, Schurch B. Clinical value of combined electrophysiological and urodynamic recordings to assess sexual disorders in spinal cord injured men. Neurourol Urodyn. 2003;22(4):314-21. [PMID: 12808706$]$

4. Courtois FJ, Goulet MC, Charvier KF, Leriche A. Posttraumatic erectile potential of spinal cord injured men: how physiologic recordings supplement subjective reports. Arch Phys Med Rehabil. 1999;80(10):1268-72. [PMID: 10527086$]$

5. Sønksen J, Chen D. Management of male infertility after spinal cord injury. Top Spinal Cord Inj Rehabil. 2002;8(1): 29-41.

6. Sønksen J, Biering-Sørensen F, Kristensen JK. Ejaculation induced by penile vibratory stimulation in men with spinal cord injuries. The importance of the vibratory amplitude. Paraplegia. 1994;32(10):651-60. [PMID: 7831070]

7. Brackett NL, Ferrell SM, Aballa TC, Amador MJ, Padron OF, Sønksen J, Lynne CM. An analysis of 653 trials of penile vibratory stimulation in men with spinal cord injury. J Urol. 1998;159(6):1931-34. [PMID: 9598490]

8. Ohl DA, Bennett CJ, McCabe M, Menge AC, McGuire EJ. Predictors of success in electroejaculation of spinal cord injured men. J Urol. 1989;142(6):1483-86. [PMID: 2585621]

9. Ohl DA, Sønksen J, Menge AC, McCabe M, Keller LM. Electroejaculation versus vibratory stimulation in spinal cord injured men: sperm quality and patient preference. J Urol. 1997;157(6):2147-49. [PMID: 9146603]

10. Sønksen J, Ohl DA, Giwercman A, Biering-Sørensen F, Kristensen JK. Quality of semen obtained by penile vibratory stimulation in men with spinal cord injuries: observations and predictors. Urology. 1996;48(3):453-57. [PMID: 8804501]

11. Sønksen J, Sommer P, Biering-Sørensen F, Ziebe S, Lindhard A, Loft A, Andersen AN, Kristensen JK. Pregnancy after assisted ejaculation procedures in men with spinal cord injuries. Arch Phys Med Rehabil. 1997;78(10): 1059-61. [PMID: 9339152]

12. Sipski ML, Alexander CJ, Rosen RC. Sexual arousal and orgasm in women: effects of spinal cord injury. Ann Neurol. 2001;49(1):35-44. [PMID: 11198294]

13. Sipski ML, Alexander CJ, Rosen RC. Physiologic parameters associated with sexual arousal in women with incomplete spinal cord injuries. Arch Phys Med Rehabil. 1997; 78(3):305-13. [PMID: 9084355]

14. Sipski ML, Rosen RC, Alexander CJ, Gomez-Marin O. Sexual responsiveness in women with spinal cord injuries: differential effects of anxiety-eliciting stimulation. Arch Sex Behav. 2004;33(3):295-302. [PMID: 15129048]

15. Sipski ML, Rosen RC, Alexander CJ, Hamer R. A controlled trial of positive feedback to increase sexual arousal in women with spinal cord injuries. NeuroRehabilitation. 2000;15(2):145-53. [PMID: 11455091]
16. Sipski ML, Alexander CJ, Rosen RC. Physiologic parameters associated with psychogenic sexual arousal in women with complete spinal cord injuries. Arch Phys Med Rehabil. 1995;76(9):811-18. [PMID: 7668950]

17. Sipski ML, Alexander CJ, Rosen RC. Orgasm in women with spinal cord injuries: a laboratory-based assessment. Arch Phys Med Rehabil. 1995;76(12):1097-1102.

[PMID: 8540784]

18. Charlifue SW, Gerhart KA, Menter RR, Whiteneck GG, Manley MS. Sexual issues of women with spinal cord injuries. Paraplegia. 1992;30(3):192-99. [PMID: 1630847]

19. Jackson AB, Wadley V. A multicenter study of women's self-reported reproductive health after spinal cord injury. Arch Phys Med Rehabil. 1999;80(11):1420-28. [PMID: 10569436]

20. Whipple B, Gerdes CA, Komisaruk BR. Sexual response to self-stimulation in women with complete spinal cord injury. J Sex Res. 1996;33(3):231-40.

21. Stenchever MA. Primary and secondary dysmenorrhea and premenstrual syndrome. In: Stenchever MA, Mishell DR, editors. Comprehensive gynecology. 3rd ed. St Louis (MO): Mosby; 1997. p. 1011-24.

22. Mishell DR. Abnormal uterine bleeding. In: Stenchever MA, Mishell DR, editors. Comprehensive gynecology. 3rd ed. St Louis (MO): Mosby; 1997. p. 1025-42.

23. Mishell DR. Primary and secondary amenorrhea. In: Stenchever MA, Mishell DR, editors. Comprehensive gynecology. 3rd ed. St Louis (MO): Mosby; 1997. p. 1043-68.

24. Durkan JP. Menstruation after high spinal cord transection. Am J Obstet Gynecol. 1968;100(4):521-24.

[PMID: 5636508]

25. Comarr AE. Observations on menstruation and pregnancy among female spinal cord injury patients. Paraplegia. 1966; 3(4):263-72. [PMID: 5910997]

26. Axel SJ. Spinal cord injured women's concerns: menstruation and pregnancy. Rehabil Nurs. 1982;7(5):10-15. [PMID: 6921826]

27. Reame NE. A prospective study of the menstrual cycle and spinal cord injury. Am J Phys Med Rehabil. 1992;71(1): 15-21. [PMID: 1739438]

28. Jackson AB. Hyperprolactinemia following SCI. In: Eighteenth Annual Scientific Meeting of the American Spinal Injury Association (ASIA)_Abstract Digest; 1992; San Diego, California. Chicago (IL): ASIA; 2002.

29. Berezin M, Ohry H, Shemesh Y, Zeilig G, Brooks ME. Hyperprolactinemia, galactorrhea and amenorrhea in women with a spinal cord injury. Gynecol Endocrinol. 1989;3(2):159-63. [PMID: 2510463]

30. Bahamondes LB, Faundes A, Tambascia M, Trevisan M, Dachs JN, Pinotti JA. Menstrual pattern and ovarian function in women with hyperprolactinemia. Int J Gynaecol Obstet. 1985;23(1):31-36. [PMID: 2860029] 
JRRD, Volume 44, Number 1, 2007

31. Boyd AE 3rd, Spare S, Bower B, Reichlin S. Neurogenic galactorrhea-amenorrhea. J Clin Endocrinol Metab. 1978; 47(6):1374-77. [PMID: 263659]

32. Garthwaite TL, Hagen TC. Plasma prolactin-releasing factorlike activity in the amenorrhea-galactorrhea syndrome. J Clin Endocrinol Metab. 1978;47(4):885-88. [PMID: 122415]

33. Yaksh TL. Opioid receptor systems and the endorphins: a review of their spinal organization. J Neurosurg. 1987;67(2): 157-76. [PMID: 3037042]

34. Naftchi NE, Lowman EW, Sell GH, Rusk HA. Peripheral circulation and catecholamine metabolism in paraplegia and quadriplegia. Arch Phys Med Rehabil. 1972;53(8): 357-61. [PMID: 5052871]
35. Bahr JM, Arbogast LA, Wang SC, Dial OK, Ben-Jonathan N. Ovarian catecholamines and ovulation. In: Schwartz NB, Hunziker-Dunn M, editors. Dynamics of ovarian function. New York (NY): Raven Press; 1981. p. 129-33.

36. Baker ER, Cardenas DD, Benedetti TJ. Risks associated with pregnancy in spinal cord-injured women. Obstet Gynecol. 1992;80(3 Pt 1):425-28. [PMID: 1495699]

37. Stenchever MA. Significant symptoms and signs in different age groups. In: Stenchever MA, Mishell DR, editors. Comprehensive gynecology. 3rd ed. St Louis (MO): Mosby; 1997. p. 148-67.

Submitted for publication October 26, 2005. Accepted in revised form February 9, 2006. 